\title{
ANÁLISES DE REVISTAS
}

\author{
NEURANATOMIA E NEUROFISIOLOAIA
}

A VIa piramidal No homem. XIV: Estudo da REPRESENTAÇÃo dOS COMPONENTES Corticais Na MEdUla (The human PYRAMidal tRact. XIV: A study of THE REPRESENTATION OF THE CORTICOSPINAL COMPONENTS IN THE SPINAL CORD). A. M. Lassex E J. P. Evans. J. Comp. Neurol., 34:11-16 (fevereiro) 1946.

Após chamarem a atenção sôbre a existência de fibras não piramidais junto às fibras constituintes do tracto piramidal, os AA. apresentam um trabalho relativo ao exame da área do tracto piramidal na medula espinal de um indivíduo portador de extenso tumor cerebral, falecido 11 meses depois de ter sido submetido a uma hemisferectomia unilateral. Esta foi quase total, apenas ficando conservados os núcleos basais e a ínsula e os vasos destinados à sua irrigação. Com o exame histológico, observaram os AA. que, na medula, a despeito da ausência de fibras descendentes nas pirâmides bulbares, havia muitas fibras na área do tracto piramidal. Essas fibras, de calibre médio e pequeno, estavam presentes seja no tracto corticospinal lateral seja no ventral, se bem que mais numerosas no primeiro, parecendo que aumentavam de número quanto mais baixo o nível medular observado. Após citarem o trabalho de Welch e Kennard, que demonstraram no macaco a incompleta degeneração das áreas do tracto piramidal na medula após a hemisferectomia, os AA. pensam na possibilidade de pertencerem as fibras remanescentes, seja ao tracto piramidal ipsilateral, scja ao sistema extrapiramidal, seja aos tractos sensitivos ascendentes, seja ainda ao sistema espinospinal.

\section{O. LEMMI}

O feixe ptramidal. Sensibilidade dos axônios à injúria máxima das suas CÉlulas de origem no gato (The pyramidal tract. The sensitivity of AXONS TO MAXIMAL INJURY OF THE CELLS OF ORIGIN IN THE CAT). A. $M$. LAssEK. J. Comp. Neurol., $34: 134-138$ (abril) 1946.

O A. inicia seu trabalho chamando a atenção sôbre a falta de trabalhos, na literatura, tendentes a estudar a velocidade de degeneração das fibras nervosas do sistema central, depois da lesão de seu centro celular. Esse estudo seria de importância, pois o conhecimento da velocidade de degeneração, ao lado da noção exata da função dos tractos nervosos, permitiria melhor correlação entre a sintomatologia e os achados de autópsia. Assim sendo, propôe-se a determinar, em experiências bem controladas, a velocidade de degeneração dos axônios do tracto piramidal do gato, após a máxima lesão de suas células de origem. O material estudado constou de 23 gatos, submetidos à ablação maciça de córtex cerebral, com o fim de destruir as células de origem do tracto piramidal. Esses animais foram, depois, estudados com intervalos variáveis de um dia até um ano, após a lesão, sendo o material corado pelo metodo do protargol. As conclusões alcançadas foram as se- 
guintes: 1. Os axônios de maior diâmetro do tracto piramidal parecem ser mais sensíveis que os menores após a perda de sua célula de origem; êles desaparecem do segundo para o terceiro dia do pós-operatório. 2. A reação axônica decorrente da lesão máxima de sua célula de origem, como a indicada pela técnica do protargol, é um teste tão sensível da degeneração secundária do tracto piramidal do gato como a dos métodos de Marchi ou da fosfatase ácida. 3. A atividade glial começa cedo e continua além de doze meses durante o processo de degeneração secundária. 4. Em geral, o alargamento do campo degenerado ocorre gradativamente, ainda que existam variações individuais. 5. Dentro dos limites da investigação, os resultados sugerem que o diâmetro das fibras nervosas pode ter importância tanto fisiológica como patológica.

\section{O. LEMMI}

O CEREBELO COMO FRENAdOR DA INÉRCIA DOS MÚSCULOS IMÓvEIS E EM MOVIMENTO (LE CERVELET FREINE L'INERTIE DES MUSCLES IMMOBILES ET EN MOUVEMENT). LEON ECTORS. Rev. Neurol., 78:14-23 (janeiro-fevereiro) 1946.

Para Ectors, a função precípua do cerebelo é a de frenação e regulação da inércia muscular, isto é, qualidade que têm todos os corpos de persistir em seu estado de repouso ou de movimento até que alguma fôrça exterior exerça sua ação modificadora. A unidade histológica - pois que o córtex cerebeloso tem estrutura uniforme em tôdas as suas partes - corresponde unidade funcional: o cerbeelo exerce uma ação frenadora igual e oposta à inércia dos músculos no decurso de reações motoras tônicas e fásicas. Ectors se propõe a demonstrar a natureza e o mecanismo de ação desta fôrça frenadora do cerebelo, mediante dados experimentais e deduções matemáticas.

Preliminarmente, são recapitulados os dados essenciais sôbre a hierarquização funcional do cerebelo. $O$ arquicerebelo, filogenèticamente a parte mais antiga do órgão, é constituído pelo flóculo, o nódulo e a língula do verme; suas vias aferentes, ipsilaterais, vêm do núcleo de Deiters e dos nervos vestibulares; as vias eferentes se terminam também no núcleo de Deiters, sendo tôdas ipsilaterais, algumas diretas, outras fazendo escala no núcleo do teto. Assim, o arquicerebelo é constituído por um arco reflexo. vestibulocerebelo-vestibular, centrado no núcleo de Deiters e no lobo flóculo-nodular, recebendo influências do sistema vestibular periférico e atuando sôbre o sistema motor periférico pela via deiterospinal. Experimentalmente, macacos se comportam igualmente quando sejam destruídos os dois labirintos ou lesado o lobo flóculo-nodular, apresentando notável desequilíbrio estático, tendência à queda e marcha de tipo ebrioso. Experièncias muito hábeis demonstraram que, no animal desprovido de arquicerebelo (cxcisão do lobo flóculo-nodular) a perda do equilíbrio se dá porque as reações vestibulares se tornaram hipermétricas, indo além do necessário. No homem, o síndromo do arquicerebelo é caraterizado por um desequilibrio estático com alargamento da base de sustentação e oscilações da cabeça e do tronco (Bailey). O neocerebelo é constituído pelos lobos laterais do cerebelo e, provàvelmente, pelo lobo mediano do verme; suas vias aferentes provêm do córtex cerebral contralateral (áreas 5, 6, 7 e 21 de Brodmann), fazento escala nos núcleos protuberanciais; suas vias eferentes se dirigem ao córtex cerebral, de onde partiram as vias aferentes, fazendo escalas, algumas na parte neocerebelar do núcleo denteado, outras na parte parvicelular do núcleo rubro, e tôdas na parte ventrolateral do tálamo. O neocerebelo é, portanto, um circuito reflexo córtico-cerebelo. cortical, centrado no córtex cerebral e no córtex clos hemisférios laterais do cerebelo, recebendo estímulos da sensibilidade consciente tanto protopática (tálamo) como epicrítica (córtex parietal) e atuando sôbre os atos motores, 
principalmente os de caráter voluntário (hipermetria, adiadococinesia, assineryia, tremor intencional). O paleocerebelo é formado pelo lobo anterior do verme e pela pirâmide vermiana; suas vias aferentes retornam à medula pela via cerebelo-rubrospinal, com escalas no núcleo do teto e na parte magnocelular do núcleo rubro. O paleocerebelo é, pois, um circuito reflexo mielo-vermiano-medular que recebe estímulos da sensibiildade proprioceptiva inconsciente e atua diretamente sôbre as células do côrno anterior, regulando o tono de sustentação.

Quando um homem apresentando uma lesão no sistema paleocerebelar põe um pé no solo, produz-se um reflexo đe sustentação exagerado com extensão de todo membro inferior correspondente, sendo o corpo projetado para o lado oposto. O mesmp reflexo se dá quando o outro pé toca o solo. $\operatorname{Re}-$ sulta o desequilíbrio, o aumento da base de sustentação e a marcha de tip. ebrioso. Os sintomas clínicos resultantes de uma lesão no paleocerebelo são análogos mas não superponíveis aos decorrentes de uma lesão no arquicerebelo. No primeiro caso, há exagêro do reflexo de sustentação, ao passo que, no segundo, há exagêro do reflexo vestibular. Nos dois casos, porém, o fundamento é o mesmo: a hipermetria por falta da ação frenadora cerebelar. Estudos fisiológicos e anátomo-clínicos permitiram a Ectors demonstrar que a ação frenadora do cerebelo não se exerce exclusivamente sôbre o córtex cerebral e núcleos diencefálicos, sôbre a medula e sôbre os centros vestibulares, mas também sôbre outros mecanismos nervosos, em particular sôbre o sistema, reticulado do bulbo e sôbre os centros vegetativos. De modo geral, se o movimento é hipermétrico depois de uma lesão cerebelosa, é porque : inércia muscular não foi inịbida e o movimento continua mesmo depois da suspensão da fôrça que o fêz nascer. Ectors procurou demonstrar a exatidão de sua hipótese, estudando, com a colaboração de matemático, a curva de alongamento e de encurtamento de um corpo elástico. Seus traçados coincidem com traçados miográficos, obtidos por Gordon Holmes, do movimento de tração dos dois braços em um doente portador de lesão no hemisfério cerebelar direito: o doente apresentava um hemissíndromo cerebeloso à direita e o traçado miográfico do braço direito mostrava, em relação ao esquerdo, nítido atraso no início e no final do movimento.

Ectors considera, também, a ação tonígena do cerebelo. O neocerebelo está em relação com o córtex cerebral e, em particular, com a área 6 , que ten ação hipotonizante; uma lesão neocerebelosa, liberando a inércia muscular no decurso de ações corticais que diminuem o tono, deve forçosamente ser hipotonizante; de fato, uma das caraterísticas do síndromo neocerebelar é a passividade muscular, estudada por André-Thomas. O paleocerebelo está em relação com a medula, geradora do tono; a lesão paleocerebelar determina hipertonia muscular, nitidamente perceptível na pesquisa dos reflexos de sustentação (Rademaker). O arquicerebelo está em relação com o núcleo de Deiters, que é hipertonizante, e as lesões do sistema arq̣uicerebelar se caraterizam pela hipertonia muscular.

\section{O. LANGE}

ONDAS LENTAS BILATERAIS PAROXÍSTICAS E SINCRÔNICAS NOS ELETRENCEFALOGRAMAS DE NÃO-EPILÉPTICOS (BILATERALLYY SYNCHRONOUS PAROXISMAL SLOW ACTIVITY IN THE ELECTROENCEPHALOGRAMS OF NON-EPILEPTICS). M. OsToW E M. Osjow. J. Nerv. a. Ment. Dis., $103: 346-58$ (abril) 1946.

A disritmia cerebral por surtos de ondas lentas bilaterais síncronas, que era tida como caraterística da epilepsia, foi pelos AA. encontrada em indivíduos não-epilépticos. Os AA. estudaram a gênese e significação dêste fenômeno de fácil comprovação, permitindo comparações objetivas com os re- 
sultados de outros.autôres, o que não se dá com outras anomalias do EEG, cujo critério de verificação ainda é variável de autor para autor. Foram examinados eletrencefalogràficamente 440 pacientes no Medical Center for Federal Prisoners, entre os quais havia psicóticos, personalidades psicopáticas, pacientes internados em clínica médica ou cirúrgica, assim como serviçais e, também, indivíduos reclusos, não podendo, portanto, ser tidos como normais. De todo êsse material, tomando por base a presença ou não da "bisynchronous paroxysmal slow activity", os AA. classificaram os EEG e os compararam estatisticamente entre epilépticos e não-epilépticos, e entre ćstes $\mathrm{e}$ indivíduos com desordens de conduta. A maior incidência da disritmia por ondas lentas foi observada no grupo de epilépticos idiopáticos (86\%), chegando a $40 \%$ em grupos de indivíduos não-epilépticos, sendo, no total dêste material, no mínimo de $15 \%$. Ora, isso contrasta grandemente com os dados de 0,5 a $1 \%$ no geral da população, 6 a $8 \%$ nos epilépticos póstrauma, $89 \%$ em epilépticos idiopáticos, $6 \%$ entre os parentes de epilépticos e $1,2 \%$ entre os portadores de moléstias orgâniças cerebrais sem epilepsia, obtidos por Gibís (1943).

Com êstes dados, que foram muito bem esmiuçados segundo cada um dos grupos de pacientes (neuróticos, homossexuais, encefalopatas vários, esquizorrênicos), os AA. puderam concluir que epilepsia idiopática e distúrbios de comportamento con reações anti-sociais são positivamente associados à presença da disritmia bissíncrona com ondas lentas. Procurando explicações teóricas para êste fato e baseados no conceito clàssicamente admitido de que a disritmia por ondas lentas depende de distúrbios subcorticais enquanto que os surtos de ondas rápidas dependem de fenómenos corticais, conclúiram que a "bisynchronous paroxismal slow discharge" é a tradução física de um componente fisiológico anormal, clinicamente silencioso, ocorrendo no subcórtex e que é capaz de: 1 - provocar descarga cortical perpétua traduzindo-se pelo ataque de grande mal; 2 - provocar séries de descargas corticais breves, dando o ataque de pequeno mal; 3 - isolar o subcórtex co controle cortical, ocasionando o episódio psicomotor. Nesta base, e tal disritmia sendo a mais freqüente em epilépticos e em personalidades psicopáticas com reações anti-sociais (e mesmo em muitos neuróticos, cuja neurose nada mais seria que a sublimação de impulsos anti-sociais), aproximarse-iam grandemente êstes dois estados mórbidos. Explica-se assim que a epilepsia seja muito mais frequiente entre criminosos que no geral da população e que as personalidades anti-sociais ocorram com maior freqüência entre epilépticos. Este trabalho, com seus dados eminentemente objetivos, confirma os resultados de Pacella, Polatin e Nagler (1944) sôbre a existência de disritmia por ondas lentas fora da epilepsia, como também traz considerações teóricas importantes no que diz respeito à comprensão fisiopatológica dêste complexo eletrencefalográfico.

\section{LíQÜIDO CEFALORRAQUIDIANO}

UMA NOVA MODIFICAÇÃo DA REAÇÃo DO BENJOTM COLOIDAL: O "NORNO-BENIOIM" E UM NOVO MÉTODO COORDENADOR: o "NORMO-OURO-BENJOIM" (EL “NORMÖEENJUI”, UNA NUEVA MODIFICACIÓN DEL “BENJUI COLOIDAL” Y FL “ NCRMO-OROrenjui", Un Nuevo método coordenador). C. LenzberG. Bol. Hospit. (Caracas, Venezuela), 44:30-74 (janeiro-fevereiro) 1945.

A reação do benjoim coloidal, da mesma forma que a rcação do mastique original, apresenta, nos líquores normais, uma zona de floculação: zona ie floculação pela solução salina. Essa curva tem o inconvenien e de encobrir posśiveis alterações de pequena intensidade. Esse fato se evidenciou, 
na reação de mastique coloidal, quando Kafka pôde eliminar a zona de floculação pela solução salina, utilizando-se de modificações na concentração de $\mathrm{NaCl}$ da solução ionizante e alterando o grau de alcalinidade do sol. $\mathrm{O} A$. propõe-se, neste trabalho, a estudar o comportamento da zona de floculação na reação do benjoim coloidal e os métodos capazes de eliminá-la. Examinando 217 líquores normais de 186 crianças internadas na Casa de Observação para Menores, pôde concluir que as curvas obtidas nos tubos do centro são devidas ao antagonismo entre os iontes $\mathrm{Na}$ de ação floculadora e certas proteínas e hidroxiliontes de ação protetora. Para eliminar a zona de floculação, utilizou-se dos seguintes métodos: diminuir a concentração da solução salina, alcalinizar a solução salina, alcalinizar o sol ou uma combinação dêsses métodos. Para verificar qual a concentração em $\mathrm{NaCl}$ na solução salina que poderia eliminar a zona de floculaçao, utilizou um ensaio prévio, no qua! determinava a sensibilidade do sol ante os iontes $\mathrm{Na}$ como fêz Kafka para a reação do mastique ou a concentração de hidroxiliontes necessária para proteger o sol dos iontes Na. Verificou, também, que a filtração do sol em filtro com carga eletronegativa, a temperatura da água utilizada para a solução do sol, a utilização de álcool absoluto ou a $96^{\circ}$, assim como o tempc, têm pouca ou nenhuma ação sôbre a modificação da zona de floculação. Já a sensibilidade do benjoim varia conforme as amostras, devendo, para cada uma delas, fazer-se os testes para a determinação da sensibilidade do sol ante os iontes $\mathrm{Na}$. Usando-se a solução ionizante na concentração determinada ou, quando a resina de benjoim é muito sensível a ponto de flocular mesmo que a solução ionizante seja água destilada, alcalinizando o sol ou a própria solução ionizante, obtém-se uma reação em que não há floculação nos tubos do centro. E o "normo-benjoim".

A segunda parte do trabalho consiste no estudo para a elaboração de um método coordenador capaz de uniformizar o mais possível os resultados das reações do ouro e do benjoim coloidal. Para isso o A. empregou uma técnica na qual usa a mesma solução salina para diluir os líquores, solução que seja o mais semelhante possível ao líquor normal quanto ao seu conteúdo em iontes $\mathrm{Na}$, alcaliniza o sol até protegê-lo dos iontes $\mathrm{Na}$ e usa as mesmas diluições e mesma leitura - em 5 graus - para as duas reações.

\section{J. M. Taques Bittencourt}

EXAME citológico do líqüIdo CEFALORRAQuidiano EM DOIS CASOS DE TUMOR CERE.

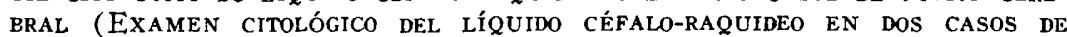
tumor cerebral). J. A. Pinto. El Día Médico (Buenos Aires), $18: 744-748$ (junho, 17) 1946.

São relatados dois casos nos quais se puderam evidenciar células neoplásticas no líqüido cefalorraquidiano. O primeiro désses casos era o de mulher com sintomatologia de compressão endocraniana, dois anos após extirpação de neoplasia do seio. O líqüido cefalorraquidiano obtido por punção lombar mostrou-se límpido e xantocrómico, com 5,40 grs. de proteínas totais por litro e 42 células por $\mathrm{mm}^{\mathrm{s}}$, das quais $18 \%$ eram tumorais.

No segundo caso, um líquor obtido por punção lombar mostrou-se alterado, com dissociação albumino-citológica -2 células por $\mathrm{mm}^{3}$ e $0,50 \mathrm{grs}$. de proteínas totais por litro - não tendo sido encontradas células anormais. Durante o ato cirúrgico, foi colhido líqüido xantocrómico com 2 grs. de proteínas totais por litro, hemácias, leucócitos e elementos tumorais.

$O$ A. passa em revista os diferentes métodos utilizados para o estudo da citologia do líqüido cefalorraquidiano e os divide em três tipos: métodos histológicos, exames em esfregaço e as colorações vitais ou supravitais. Relata a técnica por êle usada e que consiste em centrifugar o líqüido cefalorra- 
quidiano logo depois de extraído, decantando-o, e depositar o sedimento quase sêco em lâmina por intermédio de pipeta capilar fazendo esfregaço que, sêco em estufa a $37^{\circ} \mathrm{C}$, é corado pelo May-Grünwald Giemsa. Caso a taxa baixa de proteínas dificulte a obtenção de bons esfregaços, deve-se acrescentar sôro ou plasma fresco na proporção de $1 \mathrm{ml}$. para cada $0,5 \mathrm{ml}$. de sedimento, agitar bem e centrifugar novamente antes de fazer os esfregaços.

No trabalho acham-se inclúdas fotografias das células neoplásticas.

\section{J. M. Taques Bittencourt}

Proteína e aÇúcar (DEXTROSE) No LíqüIDo CEFALORRAQUidiano, NA ARTERIOSCLEROSE CEREBRAL E NA DEMÊNCIA SENIL (A STUDY OF SPINAL FLUID FROTEIN AND SUGAR (DEXTROSE) IN CEREBRAL ARTERIOSCLEROSIS AND SENILE DEMENTIA). J. F. Blalok, Jor. Dis. Nerv. Syst., 5:157 (maio) 1944.

O A. tece considerações sôbre a formação, circulação, absorção do líqüido cefalorraquidiano, e o papel da barreira hemoliquórica na modificação do teor das substâncias existentes nesse humor; em seguida, relata o resultado dos estudos feitos sôbre as variações da taxa de proteína e açúcar em casos de arteriosclerose cerebral e demência senil. Revendo os resultados. dos exames de líqüido cefalorraquidiano de 371 doentes com arteriosclerose cerebral (236) e demência senil (135), conclui que o exame do líquor nenhum: dado acrescenta para o diagnóstico diferencial, porquanto os resultados são normais nas duas enfermidades.

\section{J. M. Taques Bittencuurt}

\section{NEUROPATOLOGIA}

Sôbre a APRACTOGNOSIA geométrica E A APRAXia construtiva Consecutivas Às LESÕES DO LOBO OCCIPITAL (SUR L'APRACTOGNOSIE GEOMÉTRIQUE ET L'APRAXIF. CONSTRUCTIVE CONSÉCUTIVES AUX LESIONS DU LOBE OCCIPITAL): J. L.HERMITTE E J. Mouzon. Rev. Neurol., $73: 415-432$ (setembro-outubro) 1941.

A propósito da patologia do lobo occipital, os AA. chamam a atenção para os distúrbios práxicos decorrentes de agnosias visuais. Discutem, brilhantemente, as intrincadas questões de psicofisiologia visual. Relatam dois casos, o primeiro referente a uma hemianopsia direita completa, iniciada sùbitamente; manifestou-se, inicialmente, desvio cefalocular para a esquerda, não tendo surgido qualquer déficit motor. Na sintomatologia, destaca-se ale. xia; acromatognosia e discromatopsia; impossibiildade de identificar sólidos geométricos, reconhecer as horas no mostrador de um relógio, apreender o significado global de desenhos. Por outro lado, nomeava corretamente os objetos comuns; não havia apraxia motora, ideatória ou ideomotora, mas o paciente era incapaz de desenhar ou construir figuras geométricas. Normal a expressão da palavra, não havendo surdez verbal, acalculia, agrafia ou distúrbios da autotopo e somatognosia. Este quadro de apractognosia geométrica e construtiva decorria, segundo os AA., de lesão focal do lobo occipital esquerdo. No segundo caso, havia uma hemianopsia no quadrante inferior esquerdo; além disso, alexia, acromatognosia e impossibilidade de representação das côres. Notava-se déficit apenas na evocação da palavra; ausência de agrafia e surdez verbal. Reconhecia bem os objetos, mas não identificava formas geométricas ou desenhos; outrora clarinetista, era agora incapaz. de ler ou escrever música. Não conseguia desenhar ou construir figuras geométricas, embora não existisse outro tipo de apraxia. Decorridos 2 anos, já identificava algumas letras e côres, realizava cálculos simples, mas persistia a apractognosia geométrica; além disso, percebia bem os pormenores dos objetos, mas era incapaz de sintetizá-los. 
Os doentes não apresentavam alterações da gnosia espacial; existia apenas agnosia limitada às formas simbólicas, isto é, às representações abstratas das cousas. Fato contrário ao que se verifica na cegueira psíquica, e também diverso da agnosia geométrica do espaço (Quensel). Nos casos dos AA., teria havido como que a regressão ao estado infantil, com percepção correta das cousas e desconhecimento dos valores simbólicos. Os AA. comentam a alexia óptica (Pötzl), assinalando que o segundo doente reconhecia as letras desenhadas na pele (dermolexia) e, ademais, conseguia, às vezes, identificar desenhos, objetos e símbolos, quando seguia, com o dedo, os seus contornos; nàlogamente, a primeira doente só podia ler quando acompanhava o texto com o dedo, pois, sem êste artifício, seu olhar ficava como que prêso a uma letra ou uma palavra (Blicklähmung, de Balint); êstes fatos corroboram a existência de correlações visuomotoras. A falta de noção-deconjunto, ou seja, a incapacidade de unificar os vários elementos de um desenho, decorreria da desatenção para os campos periféricos (comum nos hemianópticos) ou de uma assimultaneognosia (Wolpert) semelhante à incapacidade de apreender o sentido de um filme. Os AA. fazem considerações, depois, sôbre a apraxia óptica ou construtiva de seus pacientes e são do parecer de Grünbaum, de que nunca ocorrem agnosias isoladas, mas, sempre, apractognosias. Entretanto, pode existir apraxia geométrica, construtiva, sem perda do pensamento espacial externo; por outro lado, pode aquela verificar-se em casos de hemiassomatognosia, isto é, de perda da consciência espacial interior. As lesões responsáveis pela apractognosia geométrica localizam-sa geralmente na regiăo peri e parastriadas (campos 18 e 19 de Brodmann), em território dos ramos posteriores da silviana, ou da cerebral posterior; os $\mathrm{AA}$. refutam que tal sintomatologia decorra de diásquise.

\section{H. Canelas}

DÉFICITS OPTOSNÓSTICOS, OPTOPRÁXICOS E OPTOPSÍQUICOS POR AMOLECIMENTO EXTENSO DA ARTÉRIA CEREBRAL POSTERIOR ESQUERDA (DÉFICITS OPTICO-GNOSIQUES, OPTICO-PRAXIQUES ET OPTICO-PSYCHIQUES PAR RAMOLLISSEMENT ETENDU UE L'artère cérébrale postérieure gauche). P. Mollaret, R. Bernard e R. Pluvinage. Rev. Neurol., $73: 356-360$ (julho-agôsto) 1941.

Trata-se de caso paralelo aos que Lhermitte e Mouzon descreveram e excelentemente estudaram. Após um icto, o paciente apresentou hemianopsia homônima direita, hemiparesia e hemissíndrome cerebelar à direita, com alteração das sensibilidades segmentar e vibratória. Este conjunto de sintomas permaneceu inalterado durante todo o período de observação. Por outro 1ado, a princípio existia alexia, sem outras manifestações afásicas, sem apraxia; psiquicamente, dismnésia e hipoprosexia. Decorridos 5 meses, episódio confusional e enriquecimento dos distúrbios gnósticos: a alexia agravou-se com o aparecimento de agnosia visual para objetos. Surgiu paralisia psíquica do olhar (Balint); impossibilidade de dispor em seriação lógica as letras, ao escrever ou utilizando cubos; acromatognosia, sem erros na representação de côres; não identificação de desenhos simbólicos ou geométricos; assimultaneognosia; apraxia construtiva (Kleist); erros de localização espacial, mesmo no lado não hemianóptico; finalmente, distúrbios da somatognosia, precedidos por transitória autotopoagnosia. Os AA. admitem que tenha ocorrido amolecimento no território da cerebral posterior esquerda, com um foco anterior e outro posterior, occipital, a princípio localizado na área estriada e, depois do segundo episódio, atingindo as áreas 18 e 19. Esta topografia foi confirmada eletrencefalogràficamente. Terminam realçando o fato de que, 
embora o homem veja com os dois hemisférios, o pensamento é uno, o que implica na unidade dos mecanismos intelectuais e de integração psíquica.

\section{H. Canelas}

Degeneração hepatolenticular. II : Fatôres nutrictonais: observações com - EMPRÉGo DE REgIME RICO EM PROTEÍNAS E METIONINA (HEPATOLENTICULAR DEGENERATION. II: NUTRITIONAL FACTORS: OBSERVATIONS ON METHIONINE AND high-PRoteins diets). F. Homburger. New England J. Med., $234: 683-687$ (maio, 23) 1946.

$O$ autor submeteu dois pacientes portadores de degeneração hepatolenticular a dieta rica em calorias, proteínas e hidratos de carbono e pobre em gorduras. Durante o tempo de observação - 14 meses em um caso e 17 meses no outro - foi tentada a terapêutica pela metionina. O primeiro caso referia-se a um paciente com 20 anos de idade cuja doença se iniciara 15 anos antes com tremores nas mãos. Dois irmãos apresentavam também a mesma moléstia. O exame neurológico mostrou sintomas extrapiramidais e anel corneano de Kayser-Fleisher. Ao exame físico, o fígado e baço não apresentavam anormalidades. A insuficiencia hepática foi documentada pela positividade da reação de floculação da cefalina e alta concentração da protrombina $(40 \%)$. Antes do tratamento, a dieta do paciente fornecia 2400 calorias com $45 \%$ de carboidratos, $17 \%$ de proteínas e $38 \%$ de gorduras; foi administrada dieta fornecendo 3.000 calorias, reduzindo a $5 \%$ as gorduras e elevando proporcionalmente as proteínas. $O$ doente foi observado durante longo tempo, apresentando nítidas melhoras tanto no estado neurológico como quanto à disfunção hepática. A concentração de protrombina se normalizou. No entanto, apesar de notável regressão dos distúrbios extrapiramidais documentada por filmes cinematográficos e da melhora subjetiva, a prova da cefalina persistiu fortemente positiva. A administração de 5 gramas diárias de metionina pareceu nada influir. Ao fim de 14 meses, o doente abandonou o tratamento e sua moléstia se agravou grandemente. Interessante notar a comparação feita por Homburguer entre a evolução da moléstia neste paciente e a de sua irmã que se recusara submeter à dita hiperproteica, pois, no paciente tratado, a moléstia apresentou nítida regressão durante os 14 meses de tratamento. A outra observação refere-se a um homem de 38 anos de idade cuja moléstia se iniciara 13 anos antes de sua internação, com tremor. Ao ser examinado, apresentava sinais extrapiramidais e sinais de insuficiència hepática. A administração de dieta fornecendo 3.000 calorias e contendo $25 \%$ de proteínas, $70 \%$ de carboidratos e $5 \%$ de gorduras, durante 4 meses, produziu notável melhora dos sintomas extrapiramidais, principalmente o tremor, como o autor pôde documentar em filmes cinematográficos. Neste caso, ao lado das melhoras subjetivas quanto ao aparelho gastrointestinal indicando melhor funcionamento hepático, a prova da cefalina, que sempre se mostrou fortemente positiva, tornou-se levemente positiva no final do tratamento. Dêstes dois únicos casos parece, pois, lícito concluir que a administração de dieta produzindo muitas calorias, rica em hidrocarbonados e em proteínas e pobre em gorduras, diminuindo a sobrecarga do fígado, permite obter resultados encorạiadnres nas moléstias do tipo da degeneração hepatolenticular.

\section{O. LANGE}

Degeneração hepatolenticular (Hepatolenticular degeneration). F. HoitBuRger E H. L. Kozol. J. A. M. A., 130:6-14 (janeiro, 5) 1946.

São relatados 4 casos de degeneração hepatolenticular, todos apresentando sinais extrapiramidais - distonia e tremores de grande amplitude e pequena 
freqüência - sinais indicadores de lesão hepática e anel corneano de KayserFleisher. Dos 4 pacientes, très eram irmãos, dos quais dois gêmeos. Todos os pacientes pertenciam à raça judia e em suas famílias foi demonstrada a grande tendência a casamentos consangǘneos. Em todos os pacientes, antes do diagnóstico de degeneração hepatolenticular feito pelos autôres, foram feitos outros diagnósticos, como psiconeurose, parkinsonismo e esclerose múltipla. Em todos os casos, as provas para a demonstração de insuficiência hepática deram resultados oscilantes. Em um dos pacientes foi feita a biópsia do fígado, que demonstrou as mesmas alteraçôes encontradas depois no exame histológico praticado post-mortem. Só um dos pacientes faleceu e o exame anatômico mostrou, além da cirrose hepática, alterações encefálicas difusas, mais intensas no putamen, onde existiam pequenas e múltiplas cavidades, com desaparecimento das células ganglionares e gliais, substituídas en alguns lugares por astrócitos hipertrofiados.

$O$ interêsse principal dêste trabalho reside na demonstração da precariedade dos resultados das provas biológicas geralmente empregadas para evidenciar a insuficiência hepática. Os autôres empregaram os testes da excreção da sulfobromoftaleína, da síntese do ácido hipúrico, da tolerância à glicose, da concentração da protrombina, da floculação da cefalina; além disso, dosaram o urobilinogênio e, no sangue, o colesterol, o teor proteico total e fracionado. De tôdas estas provas, os melhores e mais fiéis resultados parecem ser os da floculação de cefalina. O emprègo de dietas ricas em calorias ( 3 a 4.000 ), constituídas principalmente de carboidratos e proteínas, sendo o menor possível o teor gorduroso $(5$ a $10 \%)$ parece influir benèficamente, diminuindo não só os sinais de insuficiência hepática nos doentes que as apresentam, como atenuando os sinais extrapiramidais, permitindo aos doentes se movimentarem mais livremente.

\section{O. LANGE}

Histopatologia da DEgeneraÇão hepatolenticular. II - Histopatologia dos AMOLECIMENTOS CORTICAIS (HISTOPATHOLOGIE DER HEPATOLENTIKULÄREN DEGENERation. II Mit. - Histopathologie Der RINDENERWeichungen). N. W. Konowalow. Ztschr. f. d. ges. Neurol. u. Psychiat., 171, fasc. 1-3:200-228, 1941

Quando Wilson descreveu a moléstia que tem seu nome, insistiu sôbre a exclusividade das lesões nos núcleos cinzentos centrais, particularmente no putamen. No entanto, estudos posteriores mostraram que as lesões ultrapassam êsses núcleos, atingindo mesmo o córtex. Konowalow, estudando histològicamente 8 casos de moléstia de Wilson, encontrou $2 \mathrm{em}$ que as lesóes - pequenos e múltiplos focos de amolecimento - eram difusas a todo o encéfalo, apresentando todos os caracteres de processos de origem vascular. Lesões vasculares de caráter mais agudo e recente - hiperemia, alargamento das bainhas linfáticas perivasculares, alterações vasculares com endo e periarterite - foram encontradas difusamente em todo o encéfalo. Estas lesões parecem ser primitivas e, na opinião do autor, são muito semelhantes às encontradas no sistema nervoso central nos casos de intoxicação pelo álcool e pelos metais pesados.

O. LANGE

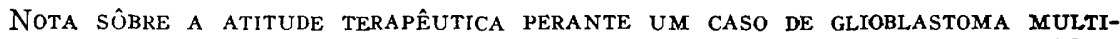
FoRme. Almeida Lima. Rev. Española de Oto-neuro-oftalmología y Neurocirugía (Valencia), 5:1-13 (janeiro-fevereiro) 1946.

Almeida Lima procura, neste trabalho, demonstrar o valor da angiografia cerebral a Egas Moniz para o diagnóstico diferencial entre os tumores intra- 
cranianos e, principalmente, para as indicações cirúrgicas nos casos de glioblastuma multiforme. Baseado em grande experiência pessoal não só quanto à técnica como no tocante à interpretação das angiografias cerebrais, o autor assinala quais os sinais que permitem o diagnóstico dos glioblastomas muliformes e focaliza as indicações da neurocirurgia em tais casos. Depois de rápida recapitulação das alterações histopatológicas encontráveis tanto no tecido tumoral como no tecido aparentemente são circunjacente aos glioblastomas multiformes e do modo pelo qual se processa a infiltração neoplástica, Almeida Lima se refere às alterações vasculares cerebrais encontráveis nesté tipo de neoplasias, alterações estas que explicam os detalhes fornecidos pela angiografia; os aspectos angiográficos demonstram estreito paralelismo com as alterações morfológicas. O estudo angiográfico dos glioblastomas multiformes permite estabelecer certo número de sinais, alguns comuns a todos os gliomas cerebrais (irrigação feita exclusivamente pelo sistema da carótida interna, vasos de calibre irregular cobrindo tôda a área ocupada pela neoplasia) e outros mais específicos dêste tipo de neoplasia (distribuição homogênea da circulação em tôda a área anormal, limites pouco nítidos da mancha de circulação neoplástica, vasos arteriais com a mesma orientação aproximadamente paralela, comunicações diretas entre artérias e veias, circulação patológica muito extensa). Estes sinais permitem selecionar os casos que devem ser submetidos à intervenção cirúrgica, a qual é de todo inútil quando a angiografia demonstre tratar-se de glioblastomas extensos e com caráter infiltrativo, sem deslocamento do sistema vascular. A excisão cirúrgica só deverá ser tentada nos casos em que a angiografia indique a existência de neoplasia mais ou menos bem circunscrita. Nos casos para os quais a angiografia indique maú prognóstico, só são aconselháveis a terapêutica médica, a roentgenterapia e as craniotomias descompressivas à Mackenzie (exerese parcial do tumor e, quando em zonas de menor importância, secção de substância cerebral em quantidade suficiente para criar dentro do crânio o maior espaço livre possível).

\section{O. LANGE}

Comirrometimento do SISTEMa Nervoso CENTRAL NA Parotidite EPIDÊMica (Mumps involvement of the central nervous system). E. M. Holden, A. Y. Eagles e J. E. Stevens Jr. J. A. M. A., 131:382 (fevereiro, 15) 1946.

O diagnóstico da natureza de um processo meníngeo é de grande importância, quer para os agrupamentos militares, quer para a prática médica ciivl. A hipótese de meningoencefalite por cachumba é muitas vezes esquecida pe!a idéia prevalente de que o processo meníngeo é secundário às manifestações clássicas da parotidite epidêmica. Entretanto, a meningoencefalite por cachumba pode ocorrer antes ou mesmo com ausência de inflamação da glândula salivar. Vai-se generalizando cada vez mais o conceito de que a cachumba é moléstia sistêmica com predileção especial para a parótida, gônidas maduras, pâncreas e seios. A concepção de Philibert, de que ela seria, primàriamente, moléstia do sistema nervoso, não encontra apôio na opinião geral. Entretanto, é freqüente observar-se o comprometimento clínico ou subclínico do sistema nervoso central no decurso da moléstia, em maior proporção de casos do que se poderia supor. Fazendo revisão da literatura, verificaram os AA. disparidade de opiniões: alguns autôres com grande número de casos sem comprometimento do sistema nervoso; outros com grande freqüência relatando a repercussão para o lado do sistema nervoso. Esta disparidade de resultados decorre, em parte, do critério adotado para avaliar o sofrimento nervoso, isto é, apenas o critério clínico para uns, enquanto outros baseavam-se no exame do líqüido cefalorraqueano. Até há bem pouco 
tempo, o problema do diagnóstico diferencial no grupo das meningites assépticas agudas era complexo, pois não havia uma prova de laboratório que permitisse a separação daquele quadro devido ao vírus da cachumba. Entretanto, Enders e col. elaboraram uma prova de fixação de complemento para o diagnóstico sorológico da cachumba, tornando possível a diferenciação da meningoencefalite devida à cachumba, da coriomeningite linfocitária, poliomielite e encefalite devidas a outros vírus. Assim, o diagnóstico mais cuidadoso da meningoencefalite por cachumba, com ou sem comprometimento da parótida, resultará do melhor conhecimento e uso desta prova sorológica.

A pesquisa dos AA. consistiu no estudo de 100 casos consecutivos de pacientes com cachumba, hospitalizados, na maioria negros. com idade entre 18 e 26 anos. Estes doentes eram examinados para se verificar se havia comprometimento clínico ou subclínico do sistema nervoso central. Todos eram submetidos à punção raqueana no $4 .^{\circ}$ dia de moléstia, sendo a punção repetida posteriormente se surgissem sinais clínicos. $O$ critério adotado para avaliação do comprometimento do sistema nervoso central foi: 1 . sinais clínicos de meningoencefalite; 2. pleocitose; 3. aumento das proteínas no líquor, considerando como anormal 10 ou mais células por $\mathrm{mm}^{3}$. e $30 \mathrm{mgrs} \%$, ou mais, de proteínas totais. Nesta base, os casos foram subdivididos em dois grupos: a) casos clinicamente reconhecidos de meningoencefalite; b) casos subclínicos, assintomáticos, porém com pleocitose ou aumento de proteinas, ou ambos, no líquor.

Dos 100 pacientes, 33 ficaram incluidos no primeiro grupo, com sinais clínicos evidentes de meningoencefalite. O número de células do líquor variou de 900 a 0 , predominando de modo absoluto os linfócitos. Observaram os AA. que não existe correlação entre a gravidade dos sinais clínicos e a intensidade da reação celular. Dêstes 33 casos, apenas 5 apresentavam células e proteínas normais no líquor. Ficaram para o seguinte grupo 10 casos assintomáticos, porém com alterações do líquor (hipercitose ou aumento de proteínas totais, ou ambos). Esta pesquisa mostra a freqüência do comprometimento do sistema nervoso central na cachumba, além de chamar a atencão para novos recursos de laboratório para o diagnóstico da meningoencefalite por cachumba, mesmo. sem comprometmiento da parótida.

\section{J. BAptista dos Reis}

CONTRIBUIÇ̃̃o À CASUÍSTICA DAS FORMAS MENINGOENCEFÁLICAS DA ENFERMIDADE DE

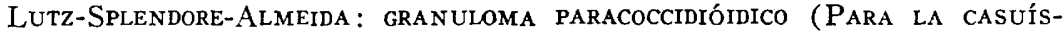
TICA DE LAS FORMAS MENINGO-ENCEFÁLICAS DE LA ENFERMEDAD DE LUTZ-SPLENdore-Almeida: GRanuloma paracoccidiolco). G. Gonzalez E J. Boggino. An. Fac. Ciencias Med. (Asunción, Paraguay), $4: 66-78$ (junho) 1944.

O número de junho 1944 dos Anais da Faculdade de Medicina de Assunção contém dois trabalhos sóbre blastomicose brasileira. O primeiro, de autoria de A. Chirife, estuda, de modo geral, a enfermidade no Paraguai, com o relato clínico dos casos conhecidos no país. $O$ trabalho divide-se em: generalidades sôbre as blastomicoses; definição, sinonímia, etiologia, patogenia, anatomia patológica, sintomatologia, evolução, formas clínicas, diagnóstico, nosografia e tratamento da paracoccidiose; casuística de paracoccidiose no Paraguai; conclusões. Dos casos relatados, em número de 11, o último apresenta localização no sistema nervoso. Sôbre êsse caso, refere-se o segundo artigo, cujo título encima esta nota. Neste segundo trabalho, os AA. referem-se à raridade da localização nervosa do fungo, transcrevem o caso publicado por Maffei e, em seguida, relatam seu caso anátomo-clínico. Tratavase de homem com 29 anos, doente há 4 anos, com dôres abdominais, lom- 
balgias e enfartamento bilateral dos gânglios ingüinais e, há ano e meio, cefaléia, raquialgia, diminuição da visão e debilidade nas pernas. $O$ exame do sistema nervoso revelou paraparesia crural com sintomas deficitários e de liberação piramidal e incoordenação muscular; síndrome meníngea com rigidez de nuca, sinais de Kernig e Brudzinski, cefaléia e vômitos; leve apraxia motora e sensorial. A radiografia do crânio mostrou sinais de hipertensão; o exame do líquor não evidenciou germes, havendo pequena dissociação albuminocitológica. A biópsia de gânglio ingüinal mostrou nódulos paracoccidióidicos. Faleceu 23 dias após admissão hospitalar. A necrópsia revelou poliadenite, amigdalite, iliite e tiflite ulcerosa, inflamação tuberculóide nas supra-renais, meningoencefalite em focos disseminados. Em tôdas essas lesões, o exane microscópico mostrou presença de paracocicidióides. Os AA. ressaltam as seguintes particularidades: escassa localização ganglionar, caráter nodular (ao exame macroscópico) e foliculóide (ao exame microscópico) das lesões meningoencefálicas, e o fato de o baço ter-se conservado indene ao paracoccidióide. A medula não foi examinada.

\section{J. M. Taques Bittencourt}

Meninges e meningites (Meninges and meningitis). H. H. Reese. YearBook Neurol., Psychiat. a. Endocrinol., 1945, pág. 143.

O A. faz una revisão geral dos últimos progressos no tratamento das meningites e um estudo crítico da orientação terapêtica. Refere-se aos excelentes resultados obtidos com a sulfadiazina na meningite meningocócica, que, porisso, ocupa posição de menor importância; à melhoria do prognóstico da meningite por Hemophilus influenzae devida à associação da sulfadiazina com o sôro de Alexander, julgando a penicilina também digna de experimentação nesta moléstia; alude a um estudo sôbre o emprêgo da estreptomicina, que se mostrou de valor nesta forma de meningite. No momento, o tratamento da meningite pneumocócica constitui um problema ainda sério. A mortalidade nesta moléstia altamente fatal foi reduzida a $50 \%$, graças ao uso combinado da penicilina mais sulfadiazina. Mostra que quase todos os estudos relativos ao emprêgo da penicilina nas meningites foram feitos com a sua administração por via intratccal, dai resultando pouca experiência para um estudo comparativo com aquêles casos tratados apenas por via muscular ou venosa. Relata, entretanto, o trabalho de Price e Hodges, em que não foi feita a penicilinoterapia intratecal e a cura foi obtida em 7 casos de meningite por cocos (4 meningo, 2 pneumo, 1 estafilocócica). Os dois pacientes que morreram eram portadores de formas muito graves e complicadas. Enumera como complicações do tratamento intratecal as seguintes seqüelas: mielomalácia, atrofia óptica, bexiga neurogênica, radiculite, fraqueza motora, distúrbios mentais. Em sua crítica sôbre a razão de ser da penicilina intratecal o autor focaliza 4 pontos: 1) Tôda substância estranha atua no espaço subaracnóideo como irritante. Os bloqueios subaracnóideos explicam, provàvelmente, as recaídas nas meningites, pois estas áreas encistadas mantêm a bactéria que reinfecta as meninges, constituindo mesmo uma barreira para a penetração da penicilina administrada em veia ou na raque; 2) O grau de difusão da penicilina injetada por via lombar é lento, comparado com a velocidade da circulação sangüínea. A presença de grande quantidade de penicilina no líquior após $24-72$ horas da punção lombar sugere estase, enquanto a presença de grande quantidade no líquor ventricular indica ser ela procedente da corrente sangǘnea, visto como o curso do líquor se faz dos ventrículos para os espaços subaracnóideos; 3) As meninges são bem vascularizadas. É mais do que provável que a reação entre o organismo e o agente antibiótico se faça nas meninges, quando a bactéria as invade. Os germes 
encontrados no líquor freqüentemente são destituídos de vitalidade; 4) Foi demonstrado, tanto em meningites, como em pacientes sem moléstia nervosa, que a penicilina injetada por via muscular ou venosa passa ao líquor em concentração útil.

A crítica do A. à penicilinoterapia intratecal vem chamar a atenção dos especialistas para melhor observação dos doentes em relação às seqüelas, procurando verificar se são devidas à medicação raqueana ou se são próprias do processo meníngeo. Parece-nos exagerado atribuir-se estas seqüelas da meningite apenas ao tratamento intratecal, pois elas já existiam nos tempos em que não havia êste tratamento. $\mathrm{Na}$ verdade, muita meningite poder-se-ia curar sem a medicação intratecal. Porém, não se tendo um meio clínico para saber antecipadamente qual a resistência do germe ao antibiótico e qual a sua virulència, todos os médicos preferem logo de início proteger o doente com uma terapéutica intensiva, atingindo logo no líquor, com a administração direta da penicilina, uma concentração alta. A expectativa inicial poderia comprometer um caso grave. Realmente, tem-se verificado no líquor a penicilina após a sua administração venosa ou muscular, porém de modo transitório e em teor relativamente baixo, comparando-se com o que se obtém após a introdução direta no espaço subaracnóideo.

\section{J. BAPtista dos Reis}

LePTOMENiNGITES MEdULARES NA BRUCELOSE: SUA RELAÇÃo COM A ESPONDILARTRITE (LEPTOMENINGITIS ESPINALES EN LA BRUCELOSIS. SUS RELACIONES OON LAS f.spondiloartritis). R. A. Piaggio Blanco, J. Dubourdieu e J. Dighiero. Arch. Urug. Med., Cir. y Especial., 24:211-230 (março) 1944.

A posição anatômica das meninges, entre as vértebras e a medula, predispõe-nas a alteraçôes nas doenças próprias dos ossos, da medula, assim como nas moléstias vértebro-medulo-radiculares. As meninges podem-se alterar posterior ou simultâneamente aos ossos e a medula. Dessa forma, três possibilidades existem: uma afecção vertebral primitiva produz leptomeningite e em seguida aparecem sintomas de sofrimento medulorradicular ou uma afecção medulorradicular primitiva produz leptomeningite e posteriormente sintomas de sofrimento vertebral, ou, ainda, uma leptomeningite primitiva produz sintomas de sofrimento vertebral e medulorradicular. A leptomeningite pode ser, então, primitiva ou secundária - mielaracnoidite ou leptomeningite vertebral, podendo aparecer em muitas moléstias, como na espondilite reumatóidea ou atrófica, na espondilite osteartrítica ou artrite hipertrófica (quadros nosológicos diferentes que haviam sido descritos englobadamente por Barré e Metzger como artrite crônica vertebral), na espondilite de von Bechterew, que pode ser incluída entre as espondilites reumatóideas, na espondilite muscular de Knaggs, na cifose juvenil osteocondropática ou enfermidade de Scheuermann, na hérnia do núcleo pulposo, na cifose da enfermidade póstraumática de Kümmel-Verneuil, na cifoscoliose dos adolescentes, nas artropatias vertebrais tabéticas e nas espondilartrites das moléstias infecciosas como tifo, disenteria bacilar, brucelose, etc.

A afecção da leptomeninge se reconhece pelas repercussões sôbre as raízes raquidianas (radiculoneurite com as seguintes formas clínicas: radicular sensitiva, radicular motora, radiculomedular mixta e radiculocordonal posterior ou atáxica), sôbre a medula, produzindo sinais deficitários e de liberação piramidal e pelas alterações do líqüido cefalorraquidiano (dissociação albuminocitológica, ou discreta reação celular em material colhido por punção lombar c, ainda, por modificação no trânsito subaracnóideo evidenciada pelas provas manométricas de Stookey e pela perimielografia). Esses processos patológicos originam-se por perturbação circulatória: compressões vasculares, isquemia 
progressiva e esclerose ulterior; por ação mecânica de formações císticas compressivas e aderências ou, ainda, por extensão progressiva da infecção das leptomeningites aos centros nervosos.

Os AA. relatam dois casos nos quais a infecção por Brucella abortus originou logo sinais de sofrimento vertebral, com lesões de osteartrite comprovadas radiològicamente e nos quais se encontrou um processo de leptomeningite que provocava aderências no espaço subaracnóideo $\left(10^{\circ}\right.$ caso) $\mathrm{e}$ reação celular e hiperalbuminose no líquor (2.0 caso). Os AA. chamam a atenção para a grande freqüência do sofrimento vertebral, assim como da leptomeninge na brucelose, aconselhando fazer exame radiológico em todo caso de brucelose em que haja dor na coluna vertebral e pensar em brucelose nos casos de afecção dolorosa da coluna por espondilartrite ou artrites reumatóideas, principalmente se o paciente, em sua profissão, estiver exposto ao contágio.

Quanto ao líqüido cefalorraquidiano, aconselham fazer sempre punção lombar, apesar da dificuldade que êsses casos oferecem, às vezes, porquanto o material colhido por via suboccipital não fornece as alterações indicativas da lesão, que são: reação citológica linfocítica ou dissociação albumino-citológica. É necessário, também, fazer-se as provas manométricas de Stookey e o estudo radiológico contrastado, além da prova serológica (reação de aglutinação). Crêem os AA. na existência da leptomeningite brucelótica, que é precoce e que se acompanha de aglutininas no líqüido cefalorraquidiano. Existe, também, outro tipo de leptomeningite que está patològicamente vinculado à espondilite, que aparece tardiamente, acompanhado de prolongado sofrimento vertebral, mas não de aglutininas no líqüido cefalorraquidiano e só de um mínimo de sofrimento nervoso. Este último tipo tem o mesmo significado das leptomeningites que aparecem no curso de diversas afecções vertebrais e nèle se enquadram os dois cásos descritos.

\section{J. M. Taques Bittencourt}

Rotura Do Disco INTERVERTEBRAL (RUPTURED INTERVERTEBRAL DISK). J. S. BarR E W. M. Craig. J. Nerv. a. Ment. Dis., 103:699-701 (junho) 1946.

Neste trabalho, que visa os aspectos clínico e médico-legal da hérnia do núcleo pulposo, os AA. recordam, inicialmente, a anatomia e fisiologia da coluna vertebral, mostrando as razões da extrema raridade dos casos em que se pode produzir rotura do disco vertebral da porção torácica, e de sua maior incidència na região lombar. Lembram, em seguida, a existência de pequenas protrusões intra-raquidianas, de natureza congênita, completamente assintomáticas, e outras, maiores, conseqüentes a traumatismo, debilidade congênita do disco e alterações degenerativas, ou da combinação destas três caussas, podendo produzir dor, seja localizada sôbre a linha mediana da região lombar, seja irradiada ao longo do grande ciático. A dor localizada nas costas é atribuída a compressão do ligamento longitudinal posterior, enquanto a que compromete o membro inferior resulta naturalmente de compressão radicular. Entrando no problema do diagnóstico, citam duas observações que ilustram a variedade das evoluções que pode seguir um caso de hérnia do núcleo pulposo: na primeira, o paciente foi acometido de dor violenta ao levantar objeto muito pesado, dor que se foi agravando progressivmaente até a intervenção cirúrgica; no segundo caso, tratava-se de protrusão intra-raquidiana de um fragmento de disco intervertebral, confirmada pelo exame radiológico de evolução descontínua, com períodos de dor e de acalmia, cujos sintomas cederam com aplicação de aparêlho ortopédico. Citam os principais sintomas e sinais que constituem o quadro clínico da rotura do disco intervertebral, comparando a freqüência com que costumam aparecer, e salientam as manobras que mui- 
tas vezes permitem descobrir uma simulação. Do ponto de vista do tratamento, indicam formalmente a intervenção cirúrgica sempre que não haja dúvida quanto ao diagnóstico; nos casos de suspeita não confirmada, a fisioterapia e os aparelhos ortopédicos devem preceder a laminectomia. Quanto ao aspecto médico-legal, lembram os AA. alguns dos problemas criados pela rotura de um disco intervertebral e as dificuldades, inerentes ao estabelecimento das relações de causa e efeito, que podem surgir na sua solução.

J. ZACLIS

\section{TERAPÊUTICA}

Tratamento da meningite por Hemophilus influenzae (The treatment of influenzal miningitis). M. H. D. Smith, P. E. Wilson e H. L. Lodes. J. A. M. A., 130:331, 1946.

A meningite por Hemophilus influenzae é moléstia relativamente freqüente da criança. $O$ tratamento com as sulfas e o anti-sôro específico de coelho tem sido usado largamente e com proveito nestes cinco aros. pósito dos AA. fazer uma apreciação global dos resultados até agora obtidos com o atual método de tratamento a fim de facilitar a apreciação do efeito de novos antibióticos porventura experimentados. Assinalam o trabalho de Rivers, de 1922, referente a 200 casos da literatura com mortalidade de $92 \%$; êste autor chamou a atenção para o fato de que a maioria dos que se salvaram tinham dois anos ou maior idade. Wilkes-Weiss e Huntington, em 1936, num:a revisão de 500 casos, verificaram que a mortalidade era de 97,6\% abaixo de 2 anos e de 19,5\% acima desta idade. De 1915 a 1939 diversas terapèuticas foram tentadas com sôros imunes de diversos animais, porém os resultados foram desanimadores. Começaram, então, a surgir as comunicações de curas devidas ao emprêgo da sulfa. Aléman fêz uma revisão da literatura até 1940 e reuniu 82 casos tratados com sulfa, havendo 10 curas, das quais 6 se referiam a pacientes com menos de 2 anos de idade. Pittman e Alexander verificaram que a sulfapiridina é superior à sulfanilamida, porén a sulfadiazina era a mais eficaz de tôdas. Sako, Stewart e Fleet (1944) observaram 23 pacientes tratados com sulfadiazina, dos quais 11 se curaram, sendo que um tinha 4 meses de idade. Alexander, orientando-se nas pesquisas anteriores de Pittman, conseguiu preparar em 1939 um sôro de coelho potente contra $H$. influenzae tipo B. Ela própria comunicou o resultado do tratamento de 50 pacientes com o sôro mais a sulfadiazina, tendo verificado mortalidade de apenas $17 \%$ nas crianças acima de 7 meses e de $75 \%$ nas de menor idade. O trabalho dos AA. inclui 28 casos de meningite por $H$. influenzae. A incidência parece ser maior no fim do outono e coméço do inverno. A meningite foi mais freqüente entre as idades de 3 a 6 meses. Em relação ao decurso clínico, assinalam grande variabilidade. Com referência ao líquor, é digna de nota a taxa de açúcar baixa bem como a ireqüência do germe no csfregaço. Com exceção de um caso, todos os demais eram do tipo B. A terapêutica consistiu em sôro de Alexander mais sulfa, que foi administrada como nas demais meningites, isto é, a sulfadiazina até atingir 8 a 12 mgrs. \% no sangue e a sulfapirazina até 3 a $6 \mathrm{mgrs} . \%$. A sulfa era continuada cêrca de 2 semanas depois da cura clínica aparente por causa da conhecida tendência a recaídas. O título de anticorpos presentes no sôro era verificado diàriamente pondo em contacto o próprio sôro do paciente com subculturas da bactéria isolada do próprio líquor. Quantidade suficiente de sôro de coelho era administrada, de sorte que uma diluição de aproximadamente 1:16 do sôro do próprio paciente produzisse a intumescência capsular. O sôro foi 
administrado por via venosa e em alguns casos por via muscular. Não recomendam a via tecal para a administração do sôro. Aconselham a prática diária de uma punção lombar e exame de líquor, pois daí decorrerá a correta dosagem do sôro e duração da sulfamidoterapia. Muitos dos pacientes, ao entra1, motravam sinais de otite média. Em algumas vezes foi necessária a perfuração da membrana do tímpano, porém nunca foi feita a mastoidectomia, julgando os AA. que esta operação só deverá ser aconselhada quando inevitável. Cuidados gerais consistiram em administração de líqüidos por via venosa e transfusões eram feitas tôdas as vezes que a taxa de hemoglobina era inferior a $10 \mathrm{gr}$.

Infelizmente, o uso do sôro de coelho anti-Hemophilus está sujeito ḋs conplicações da soroterapia. Atribuem os AA: a freqüência dêstes acidentes talvez ao fato dêste sôro ser menos purificado que aquêles outros sôros comumente em uso. Do total de pacientes apresentados, 12 apresentaram reação anafilactóide imediata ou reação retardada, ou doença do sôro, que foi a reação mais comum, e que se manifestou entre o $90^{\circ}$ e $23 .^{\circ}$ dia de hospitalização; entretanto, frisam os AA. que estas reações são de menor importância e devem ser conhecidas para melhor compreensão da evolução clínica dos casos. O resultado obtido é comparável ao que se obtém com o moderno tratamento da meningite meningocócica. De 28 casos tratados, 24 se restabeleceram em boas condições (85\%), 2 morreram e 2 outros curaram-se, porém com lesão séria do sistema nervoso central, provàvelmente irreversível. Dos recuperados, 7 apresentavam 8 meses ou menor idade. Entretanto, o alto custo do sôro anti-Hemophilus. a técnica trabalhosa das determinaçóes repetidas do título do sôro do paciente e as reações séricas fazem os AA. prever, com o advento de novo antibiótico, modificação do tratamento da meningite por $H$. influenzae.

\section{J. BAptista dos ReIS}

USo do CURARE EM SUSPENSÃo OLEOSA NO TRATAMENTO DA ESPASTICIDAdE CONSEQÜENTE A LESÕES TRAUMÁTICAS DA MEDULA (USE OF CURARE IN OIL IN TREATMENT OF SPASTicity following injury of THE SPINal CORd). E. SchlesinGER. Arch. Neurol. a. Psychiat., 55:530-534 (maio) 1946.

O emprêgo do curare em solução aquosa, por via intramuscular ou intravenosa, segundo a experiência e os resultados de Burman, Bennet, Denhoff e Bradley, trouxe, em 11 doentes paraplégicos, cessação da espasticidade, com duração de 4 a 8 horas. Tal resultado foi, entretanto, acompanhado de obnubilação da visão, diplopia, fraqueza geral e atordoações. Em vista da pequena duração do resultado útil e dos desagradáveis sintomas accessórios, o A. ideou empregar o curare em solução oleosa. Lançou mão de uma suspensão em óleo de amendoim e cera branca, idêntica à usada por Romansky e Rittman para a penicilina. O resultado, nos mesmos 11 doentes acima citados, foi um relaxamento muscular perdurando, em média, durante 3 dias e desacompanhado de qualquer dos efeitos secundários decorrentes da injeção de curare em solução aquosa. Trata-se de experiência bastante interessante, pois o relaxamento da espasticidade não só permite realizar com maior facilidade a fisioterapia e reeducação de tais pacientes, como permite, àqueles cujo distúrbio motor era devido só à espasticidade, recuperar sua motricidade de modo bastante sensível.

P. Pinto Pupo 
Estudos sôbre a disfunção neuromuscular. Tratamento pela prostigmina

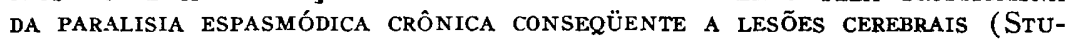
DiEs ON NEUROMUSCULAR DYSFUNCTION. NEOSTIGMINE THERAPY OF CHRONIC SPAStic paralysis from cerebral lesions). H. Kabet e C. W. Jones. J. Nerv. a. Ment. Dis., 103:107 (fevereiro) 1946.

Os AA. fazem, preliminarmente, rápido apanhado sôbre o modo de ação e emprêgo da prostigmina, especialmente na miastenia grave e em diversos tipos de disfunção neuromuscular. A finalidade dêste trabalho foi observar os resultados terapêuticos em pacientes com paralisia espástica por lesão central, os quais foram selecionados em dois grupos: hemiplégicos há mais de um ano (3 casos) e hemiplégicos com menos de um ano de moléstia (8 casos).

A dose variou desde $0,5 \mathrm{mgr}$. de metilsulfato de prostigmina com 0,32 mgr. de sulfato de atropina até $1,5 \mathrm{mgr}$. daquela mais $0,65 \mathrm{mgr}$. de atropina. Os resultados obtidos consistiram em diminuição da espasticidade, maior facilidade nos movimentos voluntários e melhora ma sensibilidade. As melhoras não foram uniformes, mas em todos os casos houve benefícios definitivos. A medicação foi também usada com resultados satisfatórios nas paraplegias espásticas cerebrais, simples ou acompanhadas de atetose ou ataxia. O trabalho apresenta 37 observaçōes, com descrição minuciosa dos pacientes antes e após o tratamento. O mecanismo de ação da prostigmina neste caso é ainda desconhecido, parecendo atuar sôbre o cérebro e medula. E curioso que se use para diminuir a espasticidade muscular tal druga, cuja ação farmacológica é oposta ao curare, que tem sido usado com a mesma finalidade.

\section{Robortella}

Hemorragia cerebral aguda curada cirùrgicamente (HÉmorragie cérébrale aigüe gứrie chirurgicalement). J. Guillaume, Ch. Ribadeau-Dumas E G. Mazars. Rev. Neurol., 78:30-32 (janeiro-fevereiro) 1946.

Observação muito instrutiva tanto quanto ao diagnóstico como prognóstico e terapéutica. Tratava-se de um indivíduo idoso, hipertenso arterial, que foi acometido de violenta cefaléia, entrando, horas depois, em torpor e estado comatoso. Ao ser internado, 8 horas após o início, apresentava-se em profundo coma, com desvio da cabeça e dos olhos para a esquerda, sinais de hemiplegia direita, respiração tipo Cheyne-Stokes, hipertensão arterial (23-12), hipertermia $\left(38^{\circ}\right)$. Foram feitas injeçōes intravenosas de sôro glicosado hipertônico, o que pareceu trazer melhoria. No dia seguinte, a sintomatologia se agravou. novamente e foi decidida a intervenção cirúrgica, após ventriculografia. Esta mostrou a existência de extensa lesão parietotemporal esquerda. A intervenção, feita após craniotomia parietotemporal posterior mostrou :A dura-máter tensa, notável congestão encefálica e tendência a herniação do encéfalo pela abertura da craniotomia. Uma incisão cortical após eletrocoagulação mostrou grande foco hemorrágico subcortical, o qual, esvaziado cuidadosamente, permitiu encontrar e ligar o vaso sangrante. Logo após a evacuação da massa sangüínea, o encéfalo se amoldou, diminuindo sua tensão, e o doente apresentou, logo, sinais de melhora. No decurso dêsse dia, o doente recuperou a lucidez e no dia seguinte já reagiu conscientemente aos estímulos externos. Um mês depois, o doente teve alta do hospital, apresentando, como reliquat, apenas hemianopsia homônima esquerda.

Tratava-se, pois, de hemorragia intracercbral recente, determinando edema cerebral e intensa congestão venosa perifocal. Interessante foi o efeito benéfico das injeções intravenosas de sôro glicosado hipertônico, conduta terapêutica geralmente contra-indicada em tais casos. $O$ exame ventriculográfico, intervenção, também, em geral, contra-indicada nas hemorragias intra- 
cranianas dos hipertensos arteriais, mostrou a localização exata do processo, localização impossivel de obter tão sòmente pelos dados clínico-neurológicos. A intervenção cirúrgica demonstrou neste caso mais uma de suas grandes indicações.

\section{O. LANGE}

Fracassos da cranioplastia precoce com tântalo (Fallure in early secondary

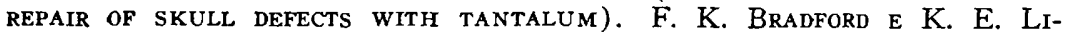
vington. J. Neurosurg., 3:318-328 (julho) 1946.

Os AA. apresentam 8 casos em que foi necessário remover a placa de tântalo, por terem sido os doentes operados em condições desfavoráveis. Tendo em conta êsses 8 fracassos num total de 44 cranioplastias executadas com o tântalo, os AA. chegaram às seguintes conclusões: 1 - o tântalo pode ser colocado impunemente sôbre feridas assépticas; 2 - operações secundárias para corrigir defeitos cranianos devem ser adiadas no mínimo por três meses após cicatrização por primeira intenção e por oito meses após a cura de processo francamente infeccioso; 3 - quando o paciente apresenta hérnia cerebral, o tratamento deve visar em primeiro lugar a sua causa e não o fechamento do orifício craniano; 4 - nenhuma placa, seja qual fôr a sua natureza, deve ser colocada sôbre campo séptico; 5 - o fechamento bem feito do couro cabeludo é essencial para o bom èxito da cranioplastia; 6 nos casos de fracasso, a placa deve ser removida sem perda de tempo; 7 o tântalo dá boa percentagem de sucessos, descle que os princípios cirúrgicos sejam rigorosamente observados.

Nos 8 casos apresentados, o tempo decorrido entre o acidente e a operação foi, em geral, excessivamente curto, a limpeza da ferida, tardia, o couro cabeludo, mal fechado e, em alguns casos, o fechamento foi levado a efeito apesar de haver infecção patente, visando com isto evitar a produção de hérnias. Os AA. julgam que, antes de abandonar princípios cirúrgicos fundamentados e bem estabelecidos, é preciso ter certeza que os novos não aumentarão a mortalidade ou a morbidade, o que ainda não foi demonstrado, e que os sucessos que se vêm verificando ùltimamente em matéria de cranioplastias talvez não sejam inerentes ao tântalo e sim à maior eficiência das drogas antinfecciosas modernas. $O$ fechamento de falhas ósseas feito nas primeiras oito horas após o acidente está de acôrdo com os princípios clássicos e dará resultados desde que o debridamento prévio tenha preparado um campo limpo; porém, com o tempo, o tecido cicatricial destruirá os focos bacterianos que porventura existam e o couro cabeludo será mais amplamente mobilizável e readquirirá a elasticidade. Não se justifica, na opinião dos AA., o fechamento precoce de lacuna craniana com o fim de aliviar o paciente de acessos convulsivos, pois um orifício craniano por si só não é suficiente para produzir convulsões; porém quando, através do orifício, se insinua substância cerebral, as convulsões têm sua razão de existir e a redução da hérnia poderá fazê-las desaparecer. Mas, neste caso, o tratamento deve visar a causa da hérnia e não impedir, à fôrça, a saída do cérebro através de orifício existente num crânio insuficiente para alojá-lo, visto que, com pressão intracraniana normal, não se produz hérnia. Os 8 casos apresentados falharam porque as operações foram executadas em épocas inoportunas, menosprezando os bons preceitos cirúrgicos. Das cinco espécies de germes isolados por cultura de material retirado das feridas, três eram muito resistentes à ação da penicilina, razão pela qual os AA. julgam que protelar a remoção da placa é excessivamente arriscado. 
Sôbre os FENÔMENos dE PARAda DE FUNÇÃo POR CICATrizes NERVOSAS (Sur les PHENOMÈNES D'ARRÊT DE FONCTION PAR CICATRICES NERVEUSES). M. R. KLEIN E G. Guiot. Presse Méd., $19: 270$ (abril, 27) 1946.

Os AA. estudam as alterações devidas a cicatrizes no sistema nervoso, particularizadamente os fenômenos, essencialmente funcionais, de parada de função dos centros nervosos e de interrupção do influxo nervoso por uma lesão localizada no meio ou na vizinhança dos centros e dos condutores nervosos. Cicatrizes constituídas por uma bainha de esclerose peritroncular são capazes de interromper a continuidade funcional dos cilindro-eixos, a despeito de ser perfeita a continuidade anatômica. O restabelecimento da função pela libertação cirúrgica do tronco permite o reaparecimento da motricidade nos músculos até então paralisados, o mesmo acontecendo com a excitabilidade direta do nervo. Os mesmos resultados foram verificados operando lesões antigas da cauda eqüina, em que havia raízes englobadas na cicatriz, com sua função ausente, sem tendência a melhorar. Tais englobamentos se revelam, clinicamente, pela ausência de secção anatômica e ausência de alterações tróficas importantes, de anestesia total e sobretudo a persistência das reações elétricas. O calo fibroso deve ser dissecado cuidadosamente, tentando isolar os nervos e raízes. Cicatrizes medulares relativamente pequenas podem produzir síndromes de secção transversa da medula; algumas vezes se trata de ferimento muito localizado em um pequeno setor, em outras, de cicatriz meningomedular englobando a medula. Muito caraterísticos são os casos de ferimentos tangenciais produzindo simples aderência da medula à dura-máter em segmento limitado, determinando paraplegia inteiramente redutível. $\mathbf{P e}-$ quenas cicatrizes cerebrais podem produzir inibição de grandes áreas, podendo dar lugar a afasias globais, hemiplegias totais, absolutamente fora de proporção com o tamanho da lesão; o mesmo pode acontecer com cicatrizes distantes da área cortical funcionalmente deficitária. A extirpação cirúrgica da cicatriz deixa um déficit na função que lhe corresponde, mas permite a volta à função normal da área antes inibida. A melhora pode ser lenta e progressiva, ou rápida. A inibição pode atingir os núcleos da base, como aconteceu em um caso, que é exposto, de uma cicatriz cérebro-cutânea parietoccipital esquerda, em criança de 13 anos, que apresentava hemiplegia, mudez e aparente imbecilidade, associada a atrofia dos tecidos do lado paralítico, tudo regredindo ràpidamente após a intervenção. Em certos casos, a inibição se dá sob a forma de ondas de agravação, pelo que novos déficits se superajuntam àqueles já existentes, exatamente como faria um tumor cerebral. Esta agravação se pode fazer regularmente ou por etapas, que ocorrem por ocasião de crises convulsivas. E apresentado o caso de um paciente com cicatriz na região parietal esquerda, que apresentava crises bravais-jacksonianas muito freqüentes, desde 1919; em 1930, teve obnubilação, alterações da memória e dificuldade em se exprimir, tendo tudo regredido em cêrca de 2 meses. Continuaram as crises convulsivas, espaçadas. Em 1941 apresentou, sùbitamente, afasia e hemiplegia direita transitória. Em 1942, após duas crises generalizadas, teve hemiplegia e afasia com hemianopsia homônima direita. Em 1943, isto se repetiu, porém, com o caráter permanente das lesões deficitárias; havia lesões tipo perda de função do cubital e hipotrofia global no lado direito do corpo, tudo acompanhado de estase papilar bilateral, mais notável à esquerda. Todos êstes sintomas desapareceram quase totalmente após a intervenção.

O mecanismo de produção dessas alterações funcionais em alguns casos pode ser atribuído à inibição edematosa do córtex, noutros a fenômenos mecânicos por repuxamento pela retração cicatricial; em outros, talvez se trate das alterações patológicas extenso-progressivas descritas por Barré. 
Em resumo, sem agir sôbre a parte funcionalmente lesada, mas por dissecção, restabelecendo a livre circulação de um tronco nervoso periférico em sua goteira vasculonervosa ou da medula em seu revestimento dural, pode ser obtido o restabelecimento da função. No cérebro, resultados semelhantes são obtidos pela excisão da cicatriz. Trata-se de trabalho interessante, que ventila uma patologia pouco conhecida. Infelizmente, se ressente do defeito de não citar a casuística tôda em que se apoiam as conclusões, nem mencionar dados estatísticos.

\section{O. BARINI}

Penicilina no tratamento da neurossífilis. II. Paralisia geral (Penicillin IN THE TREATMENT OF NEUROSYPHilis. II. DEMENTIA Paralytica). FRANK W. Reynolds, Charles F. Mohr e Joseph Earle Moore. J. A. M. A., 131 :1255-1260 (agôsto, 17), 1946.

Reynolds, Mohr e Moore estadam o efeito da penicilina isolada, comparativamente ao da penicilina associada à malarioterapia, no tratamento da paralisia geral progressiva. Empregaram o sal sódico de penicilina, em soluções aquosas, em injeções intramusculares, aplicadas de $3 \mathrm{em} 3$ horas. As doses de cada injeção variaram de 40.000 a 50.000 unidades e o número de inejções de 50 a 200 . Jamais foi utilizada a via intra-raquidiana. Nos casos em que foi empregada concomitantemente a malarioterapia, foram produzidos 8 a 12 acessos, com aproximadamente 40 horas de febre acima de $104^{\circ} \mathrm{F}$. A penicilinoterapia era iniciada desde o primeiro acesso útil da malária. $O$ uso simultâneo da malária e da penicilina é tècnicamente permitido desde que esta droga não tem ação terapêutica sôbre o Plasmodium; por outro lado, êsse processo é tanto mais recomendável se levarmos em conta as conclusões de Eagle e Musselman sôbre a exaltação do efeito treponemicida da penicilina entre as temperaturas de 37 a $42^{\circ} \mathrm{C}$. Assim, a malarioterapia associada à penicilinoterapia, além das vantagens do efeito somado de ambas as terapêuticas, teria reforçado a ação da penicilina pela hipertermia provocada. Os AA. dividiram seus doentes em dois grupos. No primeiro, formado por 24 pacientes, foi empregada apenas a penicilina, sendo obtidas a1gumas melhoras clínicas em 11 casos; em geral, houve grandes melhoras nos quadros liquóricos. No segundo grupo de pacientes, composto de 17 neuroluéticos, foi empregada a penicilina associada à malarioterapia. Os efeitos clínicos e liquóricos desta terapêutica foram sensivelmente superiores aos do uso isolado da penicilina. Concluem os AA. que a associação penicilinomalarioterapia deve ser considerada como tratamento de escolha para a paralisia geral progressiva.

Roberto Melaragno Filito 